\title{
DETERMINAÇÃO DA SOLUBILIDADE DE UREIA EM MISTURAS ETANOL-ÁGUA EM TEMPERATURAS DE 278,15 A 333,15 K
}

\author{
V.E. DINIZ ${ }^{1}$, A.P. SILVA $^{1}$, R.A. MALAGONI ${ }^{1}$ \\ ${ }^{1}$ Universidade Federal de Uberlândia / Faculdade de Engenharia Química \\ E-mail para contato: malagoni@feq.ufu.br
}

\begin{abstract}
RESUMO - Ureia é uma substância orgânica sólida, branca, inodora, tóxica, solúvel em água, é considerado um composto nitrogenado não proteico, sendo classificado quimicamente como amida. Pesquisas sobre a solubilidade do fertilizante ureia em misturas de solventes são importantes por gerar dados experimentais que podem ser usados em indústrias químicas. $\mathrm{O}$ objetivo foi obter a solubilidade da ureia em misturas etanol-água, frações de 12,6 e $71,6 \%$ de etanol $(\mathrm{m} / \mathrm{m})$, em temperaturas variando de 278,15 a 333,15 K. Um método estático de análise que consiste em uma célula de equilíbrio encamisada foi utilizado na determinação da solubilidade. Para cada temperatura, quatro amostras foram retiradas, as quais foram secas em uma estufa a $328 \mathrm{~K}$ por $48 \mathrm{~h}$. As amostras contendo ureia cristalizada foram colocadas em um dessecador com sílica, na sequência, foram determinados os valores de solubilidade e o desvio padrão. Os resultados obtidos foram comparados com dados da literatura.
\end{abstract}

\section{INTRODUÇÃO}

O estudo e determinação de modelos preditivos para a solubilidade de solutos em solventes são extremamente importantes em diversos setores ligados à engenharia industrial. A solubilidade aquosa de compostos orgânicos é um dado importante em indústrias químicas, farmacêuticas, alimentícias e em aplicações ambientais (Ran et al., 2002). Além disso, a falta de dados experimentais de solubilidade de solutos em solventes limita o estudo de modelos preditivos.

O levantamento de dados de solubilidade contribui para a promoção de diversos estudos científicos, uma vez que existem várias referências onde a solubilidade da ureia e seu comportamento em solução influenciam o sistema. Assim, a obtenção de dados relativos à solubilidade está diretamente ligada à projeção de diversos equipamentos que compõe o seio industrial. Segundo Oliveira et al. (2008), o estudo e conhecimento de fase soluto-solvente são extremamente importantes e considerados de grande interesse nas ciências ambientais e indústria química e para Malagoni (2006), a precisão de equipamentos para a indústria química, está intimamente ligada com a qualidade dos dados experimentais usados na obtenção de parâmetros de equações. A falta de dados experimentais de solubilidade de solutos em solventes limita estudos de desenvolvimento de modelos preditivos. Alguns autores se preocupam exclusivamente em obter valores para uma única temperatura sem avaliar o comportamento da solubilidade em função da temperatura. 


\section{MATERIAL E MÉTODOS}

Para a realização dos experimentos foram utilizados: ureia com pureza de 99,5\% (Nuclear) e etanol com pureza de 95\% (Vetec). A unidade experimental utilizada na determinação dos dados de solubilidade do sistema ureia em etanol é apresentada na Figura 1.

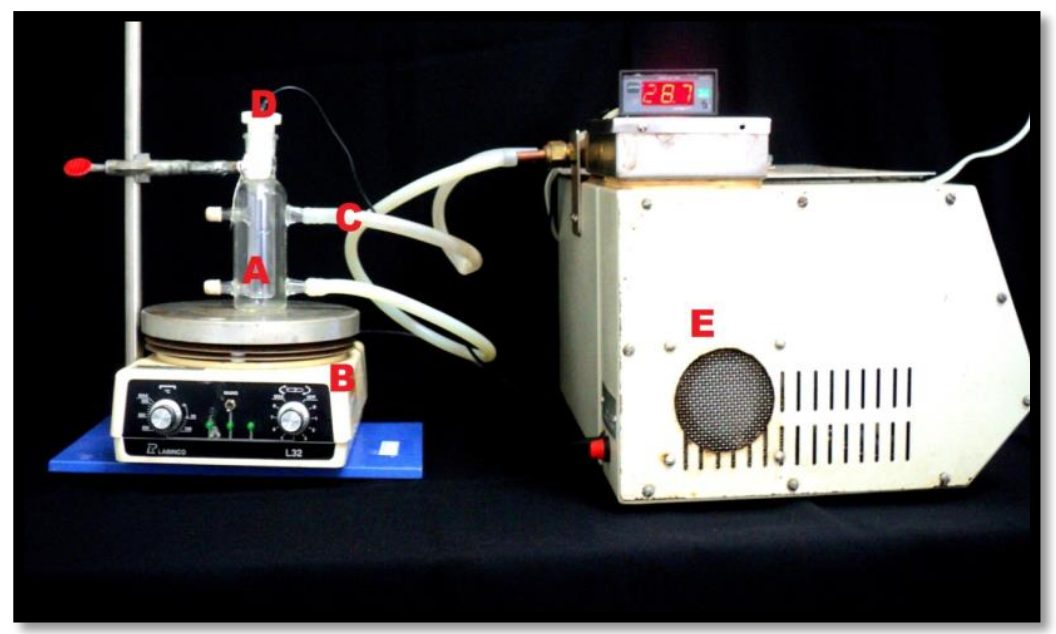

Figura 1 - - Unidade Experimental usada para os ensaios de solubilidade: (A) Célula de equilíbrio;

(B) Agitador magnético; (C) Mangueiras de látex; (D) Termopar; (E) Banho termostatizado.

O procedimento experimental proposto, foi o mesmo utilizado por Oliveira et al. (2008), Malagoni \& Franco Jr. (2007) e Ribeiro Neto et al. (2010), ao estudarem a solubilidade de compostos orgânicos em água e mistura de solventes.

A faixa de temperatura estudada neste trabalho foi de $278,15 \mathrm{~K}$ a $333,15 \mathrm{~K}$ onde se determinou a solubilidade da ureia em misturas etanol-água em concentração gravimétrica (12,6 e $71,6 \% \mathrm{~m} / \mathrm{m}$ ) considerando-se que o etanol utilizado tem cerca de $5 \%$ de água em peso. A ureia foi adicionada em excesso na solução, permaneceu em agitação por 2 horas através de um agitador magnético. Em seguida, a agitação do sistema foi desligada e o mesmo foi mantido em equilíbrio por 2 horas, o controle de temperatura da célula foi possível através de um banho termostatizado. Para monitoração da temperatura no interior da célula utilizou-se um termopar calibrado com precisão $0,1^{\circ} \mathrm{C}$.

Quatro amostragens de aproximadamente $5 \mathrm{~mL}$ foram retiradas para cada temperatura, através de uma seringa de vidro de $5 \mathrm{~mL}$, assim permitiu-se melhor verificação da reprodutibilidade do procedimento. Antes de retirar as amostras da célula de equilíbrio, pesaramse os béqueres secos e limpos. Após a introdução das amostras nos béqueres, estes foram pesados e levados para a estufa, submetidos à secagem por 48 h a 338,15 K. Após a etapa de secagem pesaram-se novamente os béqueres, os quais possuíam apenas ureia cristalizada, usando-se uma balança analítica (Gehaka, AG200) com precisão de 0,0001g.

As amostras foram pesadas por cerca de quatro dias, até que sua massa não apresentasse mais variações. Com os dados coletados foi possível determinar a massa de ureia cristalizada e a massa de solvente presente em cada amostra. Este procedimento foi realizado para cada 
temperatura estudada e para determinação da solubilidade em cada uma destas amostras, foi realizada a média aritmética dos valores de solubilidade encontrados, através da Equação 1.

$$
S=\frac{m_{u}}{m_{s}} \times 100
$$

sendo: $S$ a solubilidade (g/100 g), $m_{u}$ a massa da ureia $(\mathrm{g})$ e $m_{s}$ a massa do solvente $(\mathrm{g})$.

\section{RESULTADOS E DISCUSSÃO}

\subsection{Concentração de $12,6 \%$ em etanol}

A Tabela 1 contém os dados de solubilidade da ureia obtidos experimentalmente para a mistura etanol-água para a concentração $12,6 \%$ de etanol $(\mathrm{m} / \mathrm{m})$. Nessa tabela também foram reportados os desvios padrão do valor de solubilidade para cada temperatura estudada.

Tabela 1 - Solubilidade da ureia em mistura etanol-água (12,6\% em etanol).

\begin{tabular}{ccc}
\hline $\boldsymbol{T} \pm \boldsymbol{\delta}(\mathbf{K})$ & $\boldsymbol{S}(\mathbf{g} / \mathbf{1 0 0} \mathbf{g}$ solvente $)$ & $\boldsymbol{\sigma}(\mathbf{g} / \mathbf{1 0 0} \mathbf{g}$ solvente $)$ \\
\hline $279,2 \pm 0,2$ & 73,005 & 17,517 \\
$283,6 \pm 0,3$ & 99,631 & 1,279 \\
$288,3 \pm 0,3$ & 84,553 & 1,007 \\
$293,8 \pm 0,4$ & 96,718 & 2,230 \\
$299,1 \pm 0,6$ & 115,464 & 2,705 \\
$303,2 \pm 0,5$ & 159,980 & 0,261 \\
$308,2 \pm 0,5$ & 139,278 & 2,551 \\
$313,4 \pm 0,4$ & 158,557 & 0,158 \\
$319,3 \pm 0,6$ & 181,439 & 13,958 \\
$323,3 \pm 0,3$ & 195,065 & 4,753 \\
$328,3 \pm 0,5$ & 227,067 & 5,322 \\
$333,6 \pm 0,2$ & 244,805 & 3,786 \\
\hline
\end{tabular}

De acordo com a Tabela 1, nota-se que a solubilidade da ureia em misturas etanol-água para esta concentração, aumenta com o aumento de temperatura. Observa-se também que os desvios padrão assumiram valores relativamente baixos para as condições limites do procedimento. A Tabela 2 apresenta os dados disponíveis na literatura de Lee e Lahti (1972) para o sistema ureia em mistura de etanol-água nas concentrações de 33,3\% e 66,7\% (v/v) de etanol, as concentrações foram transformadas para $\mathrm{m} / \mathrm{m}$, resultando em $26,64 \%$ e $53,36 \%(\mathrm{~m} / \mathrm{m})$ respectivamente. Estes dados foram usados para efeitos de comparação e veracidade dos dados encontrados neste trabalho.

A Figura 2 apresenta os dados de solubilidade da ureia em mistura etanol-água (12,6\% de etanol), obtidos neste trabalho, juntamente com os dados obtidos por Lee e Lahti (1972).

Analisando-se os dados obtidos neste trabalho com os dados reportados na literatura, podese observar que os resultados não foram satisfatórios para a concentração com 12,6\% de etanol, 
pois se esperava que os dados estivessem localizados acima dos valores de solubilidade com a fração de 33,3\% de etanol, já que a ureia é mais solúvel em água do que em etanol. Porém, podese destacar que a curva de solubilidade para a fração de $12,6 \%$ de etanol apresenta o mesmo comportamento quando comparada com as frações de $33,3 \%$ e $66,7 \%$ de etanol presentes na literatura, ou seja, a medida que a temperatura é elevada a solubilidade da ureia na mistura etanolágua também eleva-se.

Tabela 2 - Solubilidade da ureia em misturas etanol-água (adaptado de Lee e Lahti, 1972).

\begin{tabular}{cccc}
\hline \multicolumn{2}{c}{$\begin{array}{c}\text { Etanol + água } \\
(\mathbf{2 6 , 6 4 \%} \text { de etanol })\end{array}$} & \multicolumn{2}{c}{$\begin{array}{c}\text { Etanol + água } \\
(\mathbf{5 3 , 3 6 \%} \text { de etanol) }\end{array}$} \\
\hline$T(\mathrm{~K})$ & $S(\mathrm{~g} / 100 \mathrm{~g}$ solvente $)$ & $T(\mathrm{~K})$ & $S(\mathrm{~g} / 100 \mathrm{~g}$ solvente $)$ \\
\hline 279,3 & 59,172 & 278,6 & 34,553 \\
288,2 & 74,685 & 288,9 & 44,196 \\
298,0 & 94,838 & 298,1 & 55,068 \\
308,2 & 119,901 & 308,4 & 70,839 \\
317,7 & 147,505 & 318,7 & 92,150 \\
327,7 & 187,903 & 328,2 & 118,001 \\
337,0 & 230,201 & 336,9 & 149,604 \\
\hline
\end{tabular}

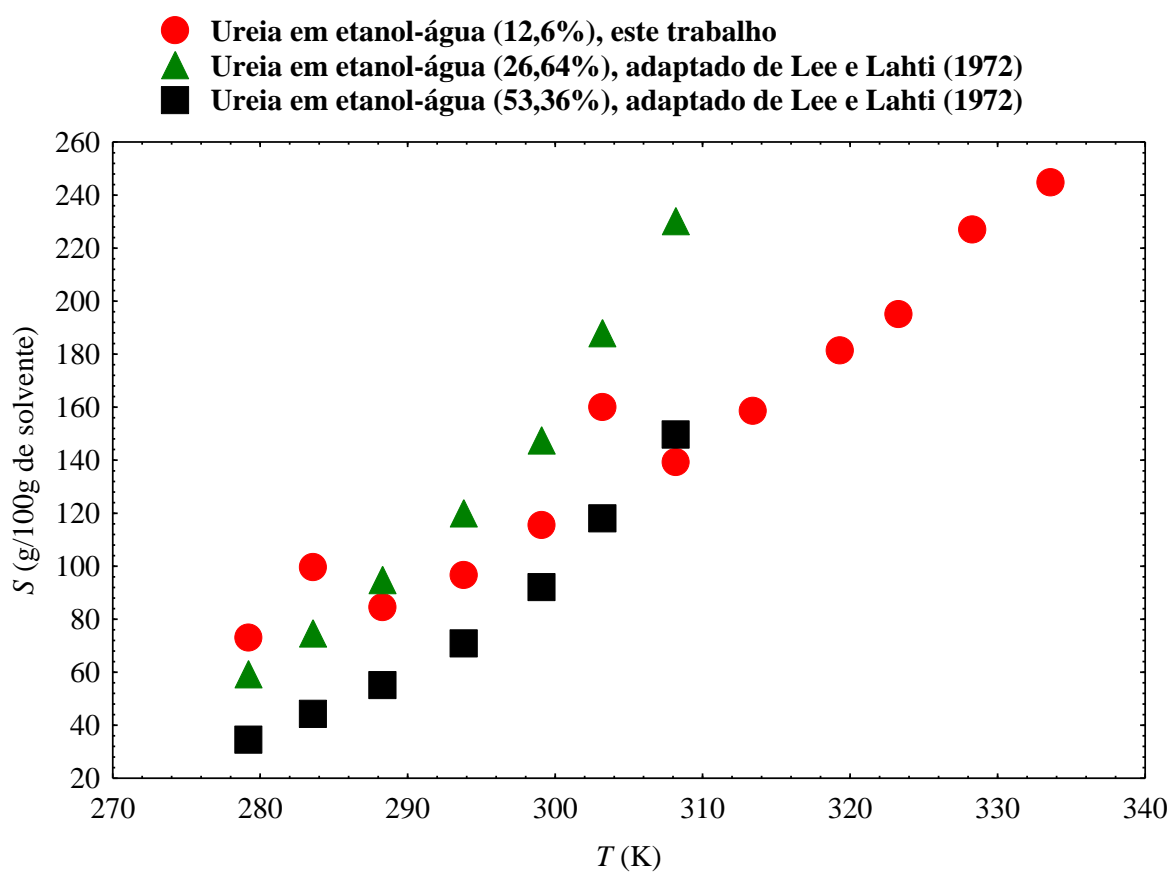

Figura 2 - Solubilidade da ureia em misturas etanol-água, (12,6\% de etanol).

\subsection{Concentração de $71,6 \%$ em etanol}

A Tabela 3 contém os dados de solubilidade da ureia obtidos experimentalmente para a mistura etanol-água para a concentração $71,6 \%$ de etanol. Nessa tabela, assim como para a Tabela 1 apresentada anteriormente, também foram reportados os dados relacionados aos desvios padrão para cada temperatura estudada. 
Tabela 3 - Solubilidade da ureia em mistura etanol-água (71,6\% em etanol).

\begin{tabular}{ccc}
\hline $\boldsymbol{T} \boldsymbol{\boldsymbol { \delta }}(\mathbf{K})$ & $\boldsymbol{S}(\mathbf{g} / \mathbf{1 0 0} \mathbf{g}$ solvente $)$ & $\boldsymbol{\sigma}(\mathbf{g} / \mathbf{1 0 0}$ g solvente $)$ \\
\hline $279,5 \pm 0,6$ & 15,975 & 4,333 \\
$283,4 \pm 0,5$ & 18,896 & 3,084 \\
$288,8 \pm 0,2$ & 20,327 & 1,047 \\
$293,7 \pm 0,1$ & 23,851 & 1,034 \\
$298,6 \pm 0,3$ & 23,862 & 9,395 \\
$303,2 \pm 0,1$ & 30,430 & 0,869 \\
$308,4 \pm 0,1$ & 34,886 & 0,173 \\
$313,3 \pm 0,2$ & 45,072 & 0,215 \\
$318,2 \pm 0,2$ & 52,569 & 0,706 \\
$323,1 \pm 0,6$ & 60,998 & 1,547 \\
$328,2 \pm 0,3$ & 75,261 & 0,449 \\
$333,5 \pm 0,2$ & 80,654 & 35,299 \\
\hline
\end{tabular}

De acordo com o exposto pela Tabela 3, nota-se que a solubilidade da ureia para esta concentração estudada aumenta com o aumento de temperatura. Além disso, pode-se constatar elevados desvios padrão presentes nos limites do range de temperatura estudado. Os dados obtidos para esta concentração foram confrontados com resultados presentes na literatura Lee e Lathi (1972) para o sistema ureia em mistura de etanol-água nas concentrações de 26,64\% e 53,36\% de etanol $(\mathrm{m} / \mathrm{m})$. A Figura 3 apresenta os dados de solubilidade da ureia em mistura etanol-água (85 $\%$ de etanol), juntamente com os dados obtidos por Lee e Lahti (1972).

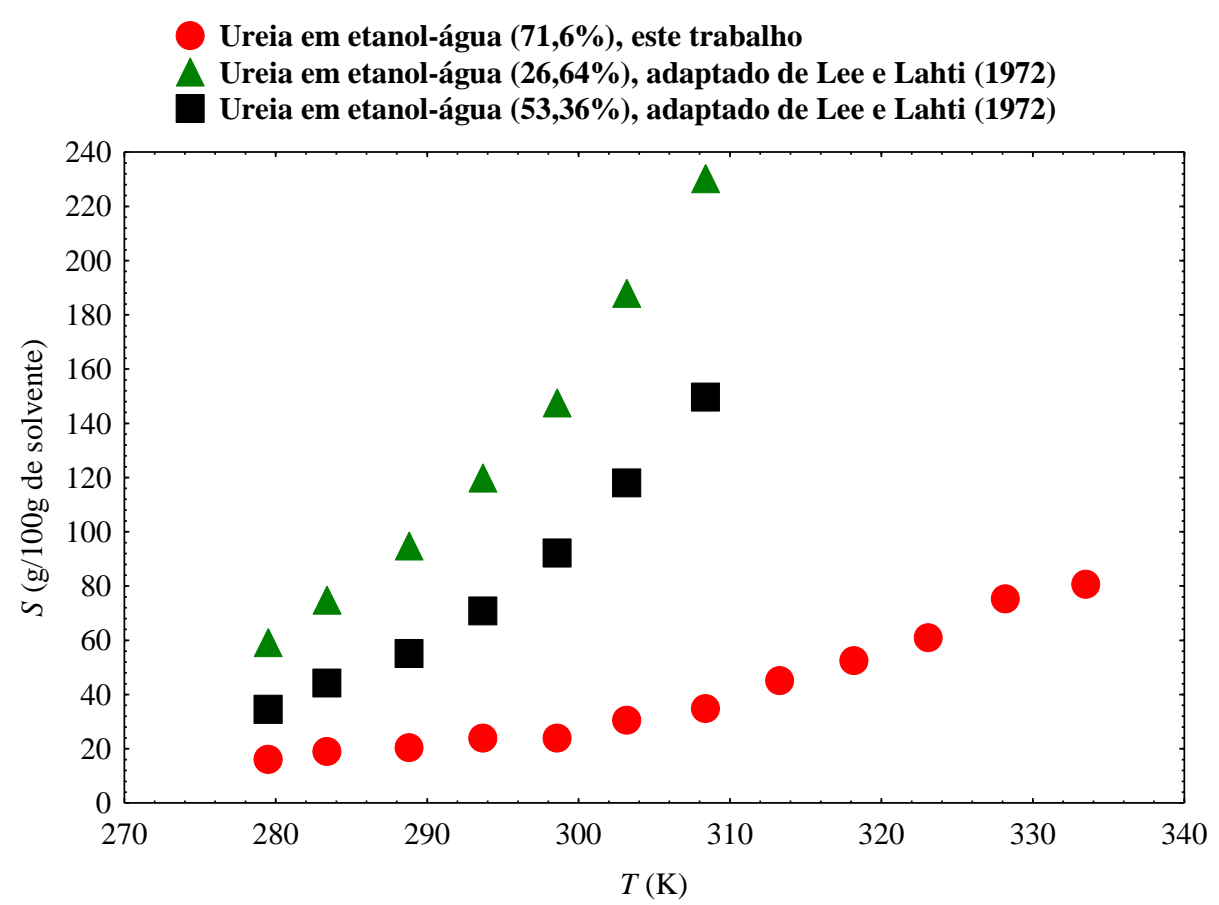

Figura 3 - Solubilidade da ureia em misturas etanol-água (71,6\% de etanol). 
Através da analise dos dados obtidos neste trabalho e confrontando-os com os dados presentes na literatura, pode-se observar que os resultados apresentaram-se coerentes, uma vez que a solubilidade da ureia na fração $71,6 \%$ etanol está abaixo dos valores de solubilidade da ureia na fração de $26,64 \%$ etanol e 53,36\% etanol, já que a ureia é menos solúvel em etanol quando comparada a água, além disso, percebe-se que os dados de solubilidade na concentração estudada apresentam o mesmo comportamento das curvas de $26,64 \%$ e $53,36 \%$ em etanol, a medida que a temperatura aumenta a solubilidade também aumenta.

\section{CONCLUSÃO}

Ao que se refere a verificação da influência da temperatura na solubilidade da ureia em misturas etanol-água, pode-se concluir que a solubilidade da ureia aumentou com o aumento de temperatura, tanto para a fração de $12,6 \%$ etanol, quanto para $71,6 \%$ etanol. Porém, para a concentração estudada de 12,6\% etanol, esperava-se que os valores de solubilidade estivessem maiores que os dados com 53,36\% e 26,64\% etanol, o que não ocorreu, assim, os dados ficaram dispostos entre as duas concentrações reportadas pela literatura.

Este fato pode ser explicado por inúmeros fatores como a contaminação do sistema no momento de realização do procedimento experimental, contaminação de pelo menos um dos reagentes usados, como por exemplo, o uso equivocado de ureia com menor grau de pureza. Além disso, pode-se citar como fator de erro a evaporação de etanol do interior da célula de equilíbrio, pois a mesma pode não se encontrar totalmente vedada, permitindo maior evaporação de etanol durante a execução dos ensaios. Esta evaporação também estaria presente no intervalo de tempo que compreende a retirada da solução do interior da célula de equilíbrio e a pesagem da amostra na balança analítica.

Com relação à concentração de 71,6\% etanol, o aparato experimental utilizado mostrou-se eficiente na determinação dos dados de solubilidade da ureia na mistura etanol-água por gravimetria, contudo, alguns desvios padrão elevados podem ser observados próximos aos limites de temperatura estudados. Pode-se relacionar este evento, à dificuldade gerada para controle de temperatura quando o procedimento era operado nos limites do range de temperatura. Além disso, nestas situações a ureia cristalizava-se facilmente no interior da seringa prejudicando a retirada de solução da célula de equilíbrio.

\section{NOMENCLATURA}

$m_{u}-$ massa de ureia $[\mathrm{g}]$

$m_{s}$ - massa da mistura de solventes [g]

$S$ - solubilidade [g/ $100 \mathrm{~g}$ de mistura de solventes]

$T$ - temperatura $[\mathrm{K}]$ 


\section{AGRADECIMENTOS}

Agradecemos a Fundação de Amparo à Pesquisa do Estado de Minas Gerais (FAPEMIG) pelos recursos concedidos no Projeto de Participação Coletiva em Eventos Técnicos-Científicos (PCE-00082-14) e a Faculdade de Engenharia Química da Universidade Federal de Uberlândia pela estrutura física disponibilizada no Laboratório de Cristalização para a realização desta pesquisa.

\section{REFERÊNCIAS}

Lee, F.-M.; Lahti, L. E. Solubility of urea in water-alcohol mixtures. Journal of Chemical and Engineering Data, 17, 3 (1972), 304-306.

Malagoni, R. A. Determinação experimental da solubilidade de orgânicos em água. 2006. 102 p. Dissertação de Mestrado, Faculdade de Engenharia Química, Universidade Federal de Uberlândia, Uberlândia, 2006.

Malagoni, R. A.; Franco Júnior, M. R. A simple apparatus for data solubility determination. Fluid Phase Equilibria, 255, 93-97, 2007.

Oliveira, M. L. N.; Malagoni, R. A.; Fehr, M.; Franco Júnior, M. R. Obtaining solubility data from a liquid-liquid equilibrium cell. Chemical Engineering Communications, 195 (2008), 10761084.

Ran, Y.; He, Y.; Yang, G.; Johnson, J. L. H.; Yalkowsky, S. H. Estimation of aqueous solubility of organics compounds by using the general solubility equation. Chemosphere, 48 (2002), 487-509.

Ribeiro Neto, A. C.; Pires, R. F.; Malagoni, R. A.; Franco Júnior, M. R. Solubility of vitamin C in water, ethanol, propan-1-ol, water+ethanol, and water+propan-1-ol at (298.15 and 308.15) K. Journal of Chemical and Engineering Data, 55 (2010), 1718-1721. 